\title{
New aspects detached from the molecular landscape of dental caries process
}

\author{
Alexandra TOTAN ${ }^{1}$, Marina Melescanu IMRE², Oana Elena AMZA ${ }^{3}$, Angelica BENCZE , \\ Ana Maria Cristina TANCU2 \\ ${ }^{1}$ Department of Biochemistry, Faculty of Dental Medicine, \\ "Carol Davila" University of Medicine and Pharmacy, Bucharest \\ 2Department of Complete Denture, Faculty of Dental Medicine, \\ "Carol Davila" University of Medicine and Pharmacy, Bucharest \\ ${ }^{3}$ Department of Endodontics, Faculty of Dental Medicine, \\ "Carol Davila" University of Medicine and Pharmacy, Bucharest \\ ${ }^{4}$ Department of Orthodontics and Dento-Facial Orthopedics, Faculty of Dental Medicine, \\ "Carol Davila" University of Medicine and Pharmacy, Bucharest
}

\begin{abstract}
Dental caries are considered an irreversible pathological process of teeth calcified tissue, characterized by demineralization and further tooth organic substance destruction, finally triggering the cavity formation.

The dynamic demineralization process occurs several times during $24 \mathrm{~h}$, but, usually, is balanced by the salivary buffering activity. However, this balance disturbance will trigger caries progression, which will induce several dentin modifications: mineral content reduction, increased micro- and nano-porosity, due to dentin collagen structure modifications, and redistribution of non-collagenous proteins. During carious lesion evolution, after dentin demineralization, the next step is the collagenous organic matrix destruction.

Dentinal and salivary proteases (mainly MMPs, together with cathepsins) should be regarded as important targets for the therapeutic strategies of carious lesions.
\end{abstract}

Keywords: dental caries, saliva, biochemical interactions

\section{INTRODUCTION}

Dentin should be regarded as a natural composite consisting of a collagen organic matrix mineralized with nanosized hydroxyapatite crystals [1].

Dental caries are considered an irreversible pathological process of teeth calcified tissue, characterized by demineralization and further tooth organic substance destruction, finally triggering the cavity formation [1]. Dentin carious lesion progression requires, as a first step, a bacterial attack along the dentin-enamel junction [1].

Then, during the demineralization phase of the cariogenic process, hydroxyapatite crystals are dissolved by the organic acids formed in the bacterial metabolism. When the local pH falls below 5.5, these bacterial organic acids are able diffuse into the mineralized dental tissues [1].

The dynamic demineralization process occurs several times during $24 \mathrm{~h}$, but, usually, is balanced by the 
salivary buffering activity [1]. Normally, saliva is able to supports the remineralization processes. However, this balance disturbance will trigger caries progression, which will induce several dentin modifications: mineral content reduction, increased micro- and nano-porosity, due to dentin collagen structure modifications, and redistribution of non-collagenous proteins $[1,2]$.

During carious lesion evolution, after dentin demineralization, the next step is the collagenous organic matrix destruction, first supposed to be the result of the bacterial proteases' activity [1,2].

\section{PROTEASES - IMPORTANT ACTORS ON THE MOLECULAR STAGE OF DENTAL CARIES}

Binderman was the first who reported a collagenolytic activity in both, healthy and carious dentin [3]. Collagenase (matrix metalloproteinase-8 (MMP-8)), gelatinases (MMP-2 and -9), stromelysin (MMP-3), and MMP-20 are most recently identified as the main actors responsible for this activity, being able to degrade all the extracellular collagen matrix components [4-13].

Dentin MMPs are synthesized by odontoblasts during dentin matrix secretion. It has been suggested that these enzymes may play key roles in dentin generation and maturation [4,6-13], however, MMPs' biochemical roles in dentin are still unclear. Experimental data have sustained their involvement in peritubular and tertiary dentin generation and the release of dentinal growth factors [14-17].

Physiological aging and disease usually induce dentin modifications, affecting its biochemical and biomechanical properties [14].

Despite the fact that mineralized dentin does not suffer significant modifications, however, inside the dentinal tubules, pre-dentin and non-mineralized dentin may be altered in response to various functional necessities [18]. It has been suggested that the alterations in the inter-tubular collagen matrix, orchestrated by MMPs, are main contributors to these structural responses [18]. Arola et al. pointed that dentin's important mechanical properties, like fatigue resistance and flexural strength, significantly change with age [18].

Cysteine cathepsins represent another important proteases family identified in dentin $[19,20]$. Cathepsins, similar to MMPs, are involved in ECM degradation, in both physiological and pathological processes [2124]. In the oral cavity environment, cathepsins have also been considered important players in carious lesions' progression and over time adhesive restorations' failure [1, 21-24].

MMPs, as well as cysteine cathepsins have been identified in saliva, mineralized dentin, and dentinal fluid. Currently, these enzymes are considered main ac- tors of the dentin cariogenic process, from the early phases of demineralization to the cavity formation $[1,25]$.

Shimada et al. highlighted that cariogenic bacteria can't degrade dentin collagenous matrix after demineralization [26]. Moreover, the bacterial cells from in situ created dentinal lesions were unable to induce collagen degradation in vitro [26]. It also has been reported that in acidic environments the purified bacterial collagenases had low catalytic activity [26]. All these data have led to the idea that the degradation of the organic matrix within dentin carious lesions may be caused especially by the host MMPs $[4,16]$.

After the collagen matrix mineralization, MMPs, as inactive forms, will be trapped within the mineralized collagen matrix [16], may be re-exposed and activated during the evolution of dentinal cariogenic processes, probably, by the acidic environment created by the bacterial organic acids $[4,6,16,21]$. Although the active MMPs are stable in acid medium, their optimal activity $\mathrm{pH}$ is neutral $[4,6,16,21]$. The acid medium neutralization can be achieved by the dentinal buffering systems or through the salivary buffering activity, thus making possible the collagen matrix degradation by $\mathrm{pH}$ - activated MMPs [1,4]. The MMPs, that could become proteolytically active during the dentin cariogenic process, include:

- collagenases (MMP-1, MMP-8)

- gelatinases (MMP-2, MMP-9) with telopeptidase activity

- stromelysin (MMP-3)

- enamelysin (MMP-20) $[4,8,12,25,27]$.

It also has been suggested that cysteine cathepsins may be involved in dentinal carious lesions initiation and progression $[20,25]$. Nascimento et al. and Vidal et al. highlighted that odontoblast or pulp-derived cysteine cathepsin activity level varies depending on the different compartments of the carious lesion $[20,25]$. Nascimento et al. reported that within carious dentin the cysteine cathepsin activity significantly increased with increasing depth toward the pulp [20].

Once the carious lesions become active, they begin to demineralize and remineralize cyclically. Their $\mathrm{pH}$ will cycle from 5.0 (inappropriate for MMPs, but optimum for cathepsin activity), to 7.0 (inappropriate for the cathepsin activity, but the optimum for MMPs). In this way, a significant proteolytic activity (due to cathepsins or MMPs activity) is insured for long periods of time.

The organic matrix degradation may be also caused by the salivary proteases' activity $[4,27,28]$. Several salivary MMPs have been identified in both gingival crevicular fluid and total saliva [29]. MMP-8 and MMP-9 are the most abundant salivary MMPs and predominate in dentin caries lesions $[4,27,28]$. Salivary MMPs 
are also able to efficiently degrade the exposed dentinal collagen fibrils [4]. Experimental data revealed higher MMP activities in active carious lesions, compared with the chronic ones [20].

It is considered that in caries-affected dentin the collagen matrix may remain mostly unaffected, until become seriously demineralized. It is most probably that the dentinal collagen fibers still retain the capacity to re-mineralize, even after almost half of the mineral content has been lost. However, an efficient remineralization impose the re-growing of nanometer-sized apatite crystals in the gap zones of the collagen network [30]. Experimental evidence indicated that in carious lesions dentin collagen molecules may undergo structural changes, like characteristic periodicity loss, even after relatively mild demineralization [24,25,30,31].

Given that at least MMP-2, MMP -9 and cysteine cathepsin $\mathrm{K}$ are able to cleave off the C-terminal end of the collagen molecule, dentinal MMPs and cysteine cathepsins should be regarded as important players in the CTX (carboxyterminal telopeptides, cleaved by cathepsins) and telopeptide fragments - ICTP (carboxy- terminal telopeptides of type I collagen, cleaved by MMPs) releasing process $[24,25,30,31]$.

\section{CONCLUSIONS}

All those presented above outline the idea that dentinal and salivary MMPs, together with cathepsins, should be regarded as important targets for the therapeutic strategies of carious lesions.

Due to MMPs and cathepsins involvement in caries progression and bond stability, these enzymes' inhibitors may play a crucial role in the new preventive and therapeutic protocols' elaboration.

However, more experimental and clinical studies are needed on new compounds able to inhibit these proteases' activity inhibition and, thus, to contribute effectively to caries prevention and improved stability of the adhesive interface.

\section{Acknowledgement}

All authors have equally contributed to this article.

Conflict of interest: none declared Financial support: none declared

\section{REFERENCES}

1. Chaussain-Miller C, Fioretti F, Goldberg M, Menashi S. The Role of Matrix Metalloproteinases (MMPs) in Human Caries. Journal of Dental Research. 2006; 85(1):22-32.

2. Tjäderhane $L$, Nascimento $F$, Breschi L, Mazzoni A, Tersariol I, Geraldeli S et al. Optimizing dentin bond durability: Control of collagen degradation by matrix metalloproteinases and cysteine cathepsins. Dental Materials. 2013;29(1):116-135.

3. Dayan D, Binderman I, Mechanic G. A preliminary study of activation of collagenase in carious human dentine matrix. Archives of Oral Biology. 1983; 28(2):185-187.

4. Tjäderhane L, Larjava $H$, Sorsa $T$, Uitto $V$, Larmas M, Salo T. The Activation and Function of Host Matrix Metalloproteinases in Dentin Matrix Breakdown in Caries Lesions. Journal of Dental Research. 1998; 77(8):1622-1629.

5. Martin-De Las Heras S, Valenzuela A, Overall $C$. The matrix metalloproteinase gelatinase A in human dentine. Archives of Oral Biology. 2000;45(9):757-765.

6. Sulkala M, Larmas M, Sorsa T, Salo T, Tjäderhane L. The Localization of Matrix Metalloproteinase-20 (MMP-20, Enamelysin) in Mature Human Teeth. Journal of Dental Research. 2002; 81(9):603-607.

7. Sulkala M, Tervahartiala T, Sorsa T, Larmas M, Salo T, Tjäderhane L. Matrix metalloproteinase-8 (MMP-8) is the major collagenase in human dentin. Archives of Oral Biology. 2007;52(2):121-127.

8. Boukpessi T, Menashi S, Camoin L, TenCate J, Goldberg M, Chaussain-Miller C. The effect of stromelysin-1 (MMP-3) on non-collagenous extracellular matrix proteins of demineralized dentin and the adhesive properties of restorative resins. Biomaterials. 2008;29(33):4367-4373.

9. Boushell L, Nagaoka H, Nagaoka H, Yamauchi M. Increased Matrix Metalloproteinase-2 and Bone Sialoprotein Response to Human Coronal Caries. Caries Research. 2011;45(5):453-459.

10. Mazzoni A, Mannello F, Tay F, Tonti G, Papa $S$, Mazzotti $G$ et al. Zymographic Analysis and Characterization of MMP-2 and -9 Forms in Human Sound Dentin. Journal of Dental Research. 2007;86(5):436-440.

11. Mazzoni A, Pashley D, Tay F, Gobbi P, Orsini $G$, Ruggeri A et al. Immunohistochemical identification of MMP-2 and MMP-9 in human dentin: Correlative FEI-SEM/TEM analysis. Journal of Biomedical Materials Research Part A. 2009;88A(3):697-703.

12. Mazzoni A, Papa V, Nato F, Carrilho M, Tjäderhane L, Ruggeri A et al. Immunohistochemical and biochemical assay of MMP-3 in human dentine. Journal of Dentistry. 2011;39(3):231-237.

13. Santos J, Carrilho M, Tervahartiala T, Sorsa T, Breschi L, Mazzoni A et al. Determination of Matrix Metalloproteinases in Human
Radicular Dentin. Journal of Endodontics. 2009; 35(5):686-689.

14. Marshall G, Marshall S, Kinney J, Balooch M. The dentin substrate: structure and properties related to bonding. Journal of Dentistry. 1997;25(6):441-458.

15. Tjäderhane L, Palosaari H, Wahlgren J, Larmas M, Sorsa T, Salo T. Human Odontoblast Culture Method: The Expression of Collagen and Matrix Metalloproteinases (MMPs). Advances in Dental Research. 2001;15(1):55-58.

16. Hannas A, Pereira J, Granjeiro J, Tjäderhane $\mathrm{L}$. The role of matrix metalloproteinases in the oral environment. Acta Odontologica Scandinavica. 2007; 65(1):1-13.

17. Charadram N, Farahani R, Harty D, Rathsam C, Swain M, Hunter N. Regulation of reactionary dentin formation by odontoblasts in response to polymicrobial invasion of dentin matrix. Bone. 2012; 50(1):265-275.

18. Arola D. In: Curtis R, Watson T (eds.). Dental biomaterials: imaging, testing and modeling. Cambridge; 2008.

19. Tersariol I, Geraldeli S, Minciotti C, Nascimento F, Pääkkönen V, Martins M et al. Cysteine Cathepsins in Human Dentin-Pulp Complex. Journal of Endodontics. 2010;36(3):475-481.

20. Nascimento F, Minciotti C, Geraldeli S, Carrilho M, Pashley D, Tay F et al. Cysteine Cathepsins in Human Carious Dentin. 
Journal of Dental Research. 2011; 90(4):506-511.

21. Palosaari $H$, Pennington $C$, Larmas $M$, Edwards D, Tjaderhane L, Salo T. Expression profile of matrix metalloproteinases (MMPs) and tissue inhibitors of MMPs in mature human odontoblasts and pulp tissue. European Journal of Oral Sciences. 2003; 111(2):117-127.

22. Breschi L, Mazzoni A, Ruggeri A, Cadenaro M, Di Lenarda R, De Stefano Dorigo E. Dental adhesion review: Aging and stability of the bonded interface. Dental Materials. 2008;24(1):90-101.

23. Liu Y, Tjäderhane L, Breschi L, Mazzoni A, Li $\mathrm{N}, \mathrm{Mao} \mathrm{J}$ et al. Limitations in Bonding to Dentin and Experimental Strategies to Prevent Bond Degradation. Journal of Dental Research. 2011;90(8):953-968.
24. Pantea M, Ighigeanu D, Totan A, Greabu M, Miricescu D, Imre M et al. Interactions Between Dental Composite Resins and Saliva A comparative biochemical in vitro study. Materiale Plastice. 2019; 56(3):529-533.

25. Vidal C, Tjäderhane L, Scaffa P, Tersariol I, Pashley D, Nader $\mathrm{H}$ et al. Abundance of MMPs and Cysteine Cathepsins in Caries-affected Dentin. Journal of Dental Research. 2013;93(3):269-274.

26. Shimada Y, Ichinose S, Sadr A, Burrow M, Tagami J. Localization of matrix metalloproteinases (MMPs-2, 8, 9 and 20) in normal and carious dentine. Australian Dental Journal. 2009;54(4):347-354.

27. Chaussain-Miller C, Fioretti F, Goldberg M, Menashi S. The Role of Matrix Metalloproteinases (MMPs) in Human
Caries. Journal of Dental Research. 2006; 85(1):22-32

28. Van Strijp A, van Steenbergen T, ten Cate J. Bacterial Colonization of Mineralized and Completely Demineralized Dentine in situ. Caries Research. 1997;31(4):349-355.

29. Bertassoni L, Habelitz S, Kinney J, Marshall S, Marshall Jr. G. Biomechanical Perspective on the Remineralization of Dentin. Caries Research. 2009;43(1):70-77. 30. Suppa P, Ruggeri A, Tay F, Prati C, Biasotto $M$, Falconi $M$ et al. Reduced Antigenicity of Type I Collagen and Proteoglycans in Sclerotic Dentin. Journal of Dental Research. 2006;85(2):133-137.

31. Deyhle H, Bunk O, Müller B. Nanostructure of healthy and caries-affected human teeth. Nanomedicine: Nanotechnology, Biology and Medicine. 2011;7(6):694-701. 